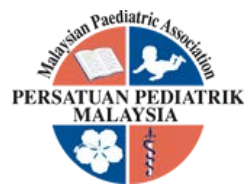

\title{
THE USE OF MODIFIED CHECKLIST FOR AUTISM IN TODDLERS (MALAY VERSION) IN DIFFERENTIATING BETWEEN AUTISM SPECTRUM DISORDERS AND OTHER DEVELOPMENTAL BEHAVIOURAL DISORDERS
}

\author{
Doris Sie Chong Lau ', Juriza Ismail', Zarina Latiff ', Raja Juanita Raja Lope ${ }^{2}$
}

\begin{abstract}
Objective: The present study examined the sensitivity and specificity of M-CHAT-Malay version [MCHAT(MV)] to discriminate ASD from other developmental-behavioural disorders. Methods: This study was carried out in the Child Development Centre at a tertiary referral centre. Parents of 130 children aged 1860 months, referred for developmental-behavioural disorders were asked to complete M-CHAT(MV). A child was considered to have ASD if they failed any 3 of the 23 total items or 2 or more of the 6 critical items. Results: Looking at the total items, M-CHAT(MV) has a good sensitivity (88.9\%) to differentiate between ASD and other developmental-behavioural disorders, although specificity was only $47.8 \%$. However, the critical items only has sensitivity of $71.4 \%$ and specificity of $77.6 \%$. Sensitivity for children aged $49-60$ months old was lower (80.0\%) compared to those in the younger age group $(100.0 \%$ and $90.3 \%$ for those aged 25-36 months and 37-48 months respectively). Based on the ROC curve, the optimal criteria to detect ASD was failing 1 out of 6 critical items or 3 out of 23 total items. Conclusion: M-CHAT(MV) is a good screening tool in differentiating ASD from other developmental-behavioural disorders although the critical items' criteria may need to be lowered to improve its sensitivity in selected cohorts.
\end{abstract}

\section{Keywords:}

Autism, Screening, M-CHAT, Malay Version, Sensitivity, Specificity

\section{Introduction}

Autism spectrum disorder (ASD) is a group of disorders of development which causes impairment in a child's social relationships, communication, play and often, academic skills [1]. Diagnosis of ASD may not be easy because children of different age groups exhibit varying ASD symptoms with differing severity [2]. Although most parents report an initial concern at the age of 18 months or younger, most children are not diagnosed until the age of 4 years and beyond [3-5]. In Malaysia, based on data from the Annual Health Survey, the prevalence of ASD in the pre-school age group alone was reported to be between 6 to 9 per 1000 children [6]. Up to $50 \%$ of ASD cases were detected after school entrance at 5 years old. An overlap of symptoms between children with ASD and those with other developmental disorders, such as global
Received: 4 October 2018; Accepted revised

manuscript: 1 April 2019

Published online: 3 June 2019 developmental delay and developmental language delay makes the diagnosis of ASD difficult, necessitating a reliable screening tool to facilitate early diagnosis and intervention [7].

The Modified Checklist for Autism in Toddlers (MCHAT) is a 23-item yes/no parent-report checklist that was adapted from the Checklist for Autism in Toddlers (CHAT) [8-10]. The M-CHAT was designed

\footnotetext{
'Department of Paediatrics, Universiti Kebangsaan Malaysia Medical Centre, Kuala Lumpur, Malaysia

${ }^{2}$ Pantai Hospital and WQ Park Health \& Rehabilitation Centre, Kuala Lumpur, Malaysia

Corresponding author: Dr Doris Lau Sie Chong,

Department of Paediatrics, Faculty of Medicine, University Kebangsaan Malaysia Medical Centre, Jalan Yaacob Latif, 56000 Cheras, Kuala Lumpur, MALAYSIA.

Email: doris@ppukm.ukm.edu.my; Tel: 03-91457410; Fax: 03-91456637
} 
to identify children with ASD and has been validated as a developmental screening tool for toddlers between 16 and 30 months of age. MCHAT is simple, easy to use and does not require specialised training for paediatricians. Initial studies which used M-CHAT for identifying children with autism amongst normal population showed high sensitivity, specificity and positive predictive value $(0.97,0.95$, and 0.80 , respectively) $[11,12]$. It has also been translated into other languages, namely Mandarin, Japanese and Spanish with similar results [13-15].

Apart from its use in the general population, it has also been used to distinguish a child with ASD from other developmental-behavioural disorders. Eaves et al examined the use of M-CHAT in a group of 84 children aged between 24 to 48 months old referred for possible autism [16]. From this group, $64 \%$ of them were diagnosed with ASD while the remaining children had other diagnoses including intellectual disability and language disorder. Sensitivity for both the critical item and total item scores were $77 \%$ and $92 \%$ respectively whereas the specificity were $43 \%$ and $27 \%$ respectively. Snow et al used M-CHAT in pre-school children aged between 18 to 48 months old who were referred for developmental-behavioural problems [17]. With the sample size of 82 children, the sensitivity of M-CHAT was $70 \%$ for the critical item score and $88 \%$ for the total item score. The specificity however was only $38 \%$ for both the critical item and total item scores.

To date, numerous studies have addressed the use of M-CHAT as a screening tool for early detection of ASD. In Malaysia, M-CHAT has been translated into Malay language - the national language for this multi-ethnic and multi-lingual country, and used as a screening tool for ASD in the primary health care setting [18]. However, no study has been done to look at the sensitivity and specificity of M-CHAT (Malay version) in differentiating ASD amongst Malaysian children from other developmental-behavioural problems.

Therefore, we aim to determine the sensitivity and specificity of the M-CHAT (Malay Version) [thereafter abbreviated as M-CHAT (MV)] as a screening tool to differentiate ASD from other developmental-behavioural disorders. We also expanded the use of this parent-administered tool to include older age group i.e. children aged 30 to 60 months old, as this is the age group when most parents or caregivers raise concerns regarding their children's developmental or behavioural problems in our population.

\section{Methods}

This study was conducted in the Child Development Centre (CDC) at a tertiary medical centre over a 2-year period from January 2011 till Nov 2012. Approval from the institutional ethics committee was obtained prior to commencement of this study and written parental consent was obtained prior to recruitment of patients. Parents of children aged 18-60 months who were newly referred for developmental-behavioural problems to our CDC were eligible for the study. Patients were referred by either general paediatricians, general practitioners or community child health nurses.

At the first clinic visit, parents (either father or mother) or the primary caregivers were approached and were given the M-CHAT (MV) to complete. Parents who refused consent were excluded. Explanation was given to the respondents who had language difficulties pertaining to the questions or those who were illiterate. The checklist was collected immediately prior to their child's review by the developmental paediatrician. The underlying diagnosis, either ASD or other developmental-behavioural disorders (e.g. attention deficit hyperactive disorder, isolated speech delay, et cetera) was made during the $1^{\text {st }}$ visit using the Diagnostic and Statistical Manual of Mental Disorder 4th edition, Text Revision (DSM IV-TR) criteria. Following this, patients were seen again 4-6 months later by a different developmental paediatricians where reevaluation was performed to validate the initial diagnosis. The M-CHAT (MV) scores were not revealed to these paediatricians during the study period. The diagnosis made during the second visit were used as the final diagnosis in this study.

\section{Research Tool}

The questionnaire used in this study comprised of 2 sections; (i) sociodemographic background questionnaire on the patients and (ii) the M-CHAT (MV). M-CHAT was designed originally by Diana $L$. Robins [9]. It was translated to the Malay version with permission by Dr Aminah Bee in 2005 and the reliability was tested on 32 mothers attending the Mother and Child Health Clinics [18]. In this study, only the Malay version was used. As with the original version of M-CHAT, the Malay version contained 23 items, of which 6 were critical items. The respondents (either father, mother or accompanying caregiver) answered "yes" or "no" 
for each item and scoring was made thereafter. The child was considered to have ASD if the child failed any 3 of the total 23 items or 2 or more of the 6 critical items.

\section{Sample size}

Calculation of sample size was based on the assumption that all children with ASD would fail at least two of the six critical items or any three of the 23 total items on the checklist as with the original scoring system [10]. A total sample size of 175 patients was required to achieve a sensitivity and specificity of $95 \%$ respectively, with $95 \%$ level of confidence and precision of 0.05 .

\section{Data analysis}

The SPSS statistical program (version 22) was used for data analysis. Chi square test [or Fisher's exact test for expected value of less than 5] was used for analysis of categorical variables, whereas the student's $t$ test was used for analysis of continuous variables. A $p$ value of less than 0.05 was considered statistically significant. The receiver operating characteristic (ROC) curves were plotted to determine the optimum criteria for identifying children with possible ASD in our study population.

\section{Results}

A total of 130 parents consented to participate in the study (Figure 1). Majority of patients were between 37 to 48 months old (59 patients), followed by 25 to 36 months old ( 38 patients) and 49 to 60 months old ( 27 patients). Only 6 patients were between 18 to 24 months old. Based on the final diagnosis made by the developmental paediatrician, the patients were categorized into two main groups, the Autism Spectrum Disorder (ASD) group and other DevelopmentalBehavioural disorder group. The latter group comprised of the following: 20 patients with Global Developmental Delay, 41 with isolated Specific Language Impairment and 6 with Attention Deficit Hyperactive Disorder). Patients under the ASD group comprised of Autistic Disorder (50 patients) and Pervasive Developmental Disorder - Not Otherwise Specified (PDD-NOS) (13 patients). Majority of the respondents were of Malay ethnicity (Table 1). Most of them were able to complete the M-CHAT (MV) without requiring any assistance or clarification.

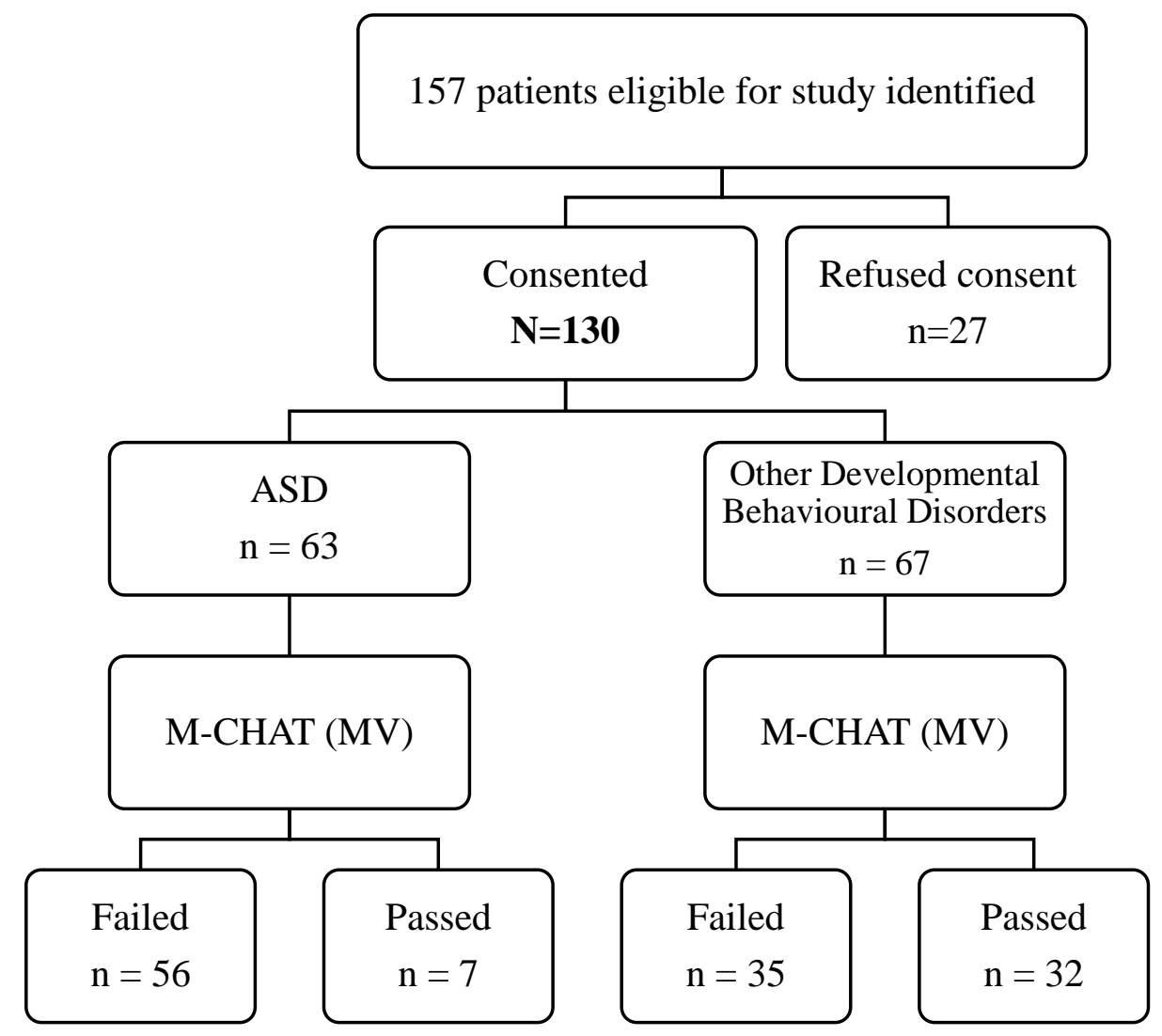

ASD-Autism Spectrum Disorder; M-CHAT (MV)-Modified Checklist for Autism in Toddlers (Malay Version)

Figure 1: Summary of patient population 
Table 1: Demographic Data of Study Population

\begin{tabular}{|c|c|c|c|}
\hline Characteristics & $\begin{array}{c}\text { ASD } \\
(n=63)\end{array}$ & $\begin{array}{c}\text { Other Developmental } \\
\text { Behavioural Disorders } \\
(n=67)\end{array}$ & $p$ value \\
\hline $\begin{array}{l}\text { Patient's age at recruitment in } \\
\text { years, mean (SD) }\end{array}$ & $3.44( \pm 0.691)$ & $3.22( \pm 0.817)$ & 0.091 \\
\hline \multicolumn{4}{|l|}{ Gender, n (\%) } \\
\hline Males & $55(87.3)$ & $49(73.1)$ & 0.044 \\
\hline Females & $8(12.7)$ & $18(26.9)$ & \\
\hline \multicolumn{4}{|l|}{ Race, n (\%) } \\
\hline Malay & $46(73.0)$ & $45(67.2)$ & 0.426 \\
\hline Chinese & $16(25.4)$ & 19 (28.4) & \\
\hline Indian & $0(0)$ & $3(4.5)$ & \\
\hline Others & $1(1.6)$ & $0(0)$ & \\
\hline $\begin{array}{l}\text { Patient's age at initial parental } \\
\text { concern in years, mean (SD) }\end{array}$ & $2.40( \pm 0.638)$ & $2.09( \pm 0.664)$ & 0.008 \\
\hline $\begin{array}{l}\text { Patient's age at referral in years, } \\
\text { mean (SD) }\end{array}$ & $3.07( \pm 0.654)$ & $2.91( \pm 0.767)$ & 0.297 \\
\hline \multicolumn{4}{|l|}{$\begin{array}{l}\text { Respondent's relationship with } \\
\text { patient, } \mathrm{n}(\%)\end{array}$} \\
\hline Mother & 45 (71.4) & $50(74.6)$ & 0.645 \\
\hline Father & $17(27.0)$ & $17(25.4)$ & \\
\hline Others & $1(1.6)$ & $0(0)$ & \\
\hline \multicolumn{4}{|l|}{$\begin{array}{l}\text { Respondent's education level, } \\
\mathrm{n}(\%)\end{array}$} \\
\hline Primary & $0(0)$ & $1(1.5)$ & 0.911 \\
\hline Secondary & $10(15.9)$ & $9(13.4)$ & \\
\hline Tertiary & $53(84.1)$ & $57(85.1)$ & \\
\hline \multicolumn{4}{|l|}{$\begin{array}{l}\text { Primary language at home, } \\
\mathrm{n}(\%)\end{array}$} \\
\hline Malay & $36(57.1)$ & $35(52.2)$ & 0.682 \\
\hline Mandarin & $8(12.7)$ & $10(14.9)$ & \\
\hline Tamil & $0(0)$ & $1(1.5)$ & \\
\hline English & $2(3.2)$ & $3(4.5)$ & \\
\hline Mix ( $\geq 2$ language) & $17(27.0)$ & $18(26.9)$ & \\
\hline $\begin{array}{l}\text { Require assistance to complete M- } \\
\text { CHAT (MV), } n(\%)\end{array}$ & $5(7.9)$ & $5(7.5)$ & 0.920 \\
\hline
\end{tabular}

ASD-Autism Spectrum Disorder; SD-Standard deviation; n-number

The overall sensitivity for the M-CHAT (MV) in this study to discriminate between ASD and other developmental behavioural disorders was $88.9 \%$ while the specificity was $47.8 \%$ (Table 2). The sensitivity for each individual age group was $80 \%$ and above for the total criteria. However, the sensitivity for critical criteria was relatively low for those aged between 37-48 months and 49-60 months old $(64.5 \%$ and $66 \%$ respectively). The overall positive predictive value was $61.5 \%$ while the negative predictive value was $82.0 \%$. Sensitivity and specificity for patients aged $18-24$ months old were not analyzed as there were only 6 patients in that group (only one patient was diagnosed with ASD). 
Table 2: Sensitivity and Specificity of M-CHAT (MV) for Different Age Groups

\begin{tabular}{lcccc}
\hline Groups & $\begin{array}{c}\mathbf{2 5 - 3 6} \text { months } \\
(\mathbf{n = 3 8 )}\end{array}$ & $\begin{array}{c}\mathbf{3 7 - 4 8} \text { months } \\
(\mathbf{n}=\mathbf{5 9})\end{array}$ & $\begin{array}{c}\mathbf{4 9 - 6 0} \text { months } \\
(\mathbf{n = 2 7})\end{array}$ & $\begin{array}{c}\text { Overall } \\
(\mathbf{n}=\mathbf{1 3 0})\end{array}$ \\
\hline $\begin{array}{c}\text { Total Items } \\
\text { Sensitivity }\end{array}$ & $100.0 \%$ & $90.3 \%$ & & \\
Specificity & $45.4 \%$ & $57.1 \%$ & $80.0 \%$ & $88.9 \%$ \\
& & & $50.0 \%$ & $47.8 \%$ \\
Critical Items & & & & \\
$\quad$ Sensitivity & $93.7 \%$ & $64.5 \%$ & $66 \%$ & $71.4 \%$ \\
Specificity & $63.6 \%$ & $85.7 \%$ & $91 \%$ & $77.6 \%$ \\
& & & & \\
PPV & $57.1 \%$ & $70.0 \%$ & $66.7 \%$ & $61.5 \%$ \\
NPV & $100.0 \%$ & $84.2 \%$ & $66.7 \%$ & $82.0 \%$ \\
\hline
\end{tabular}

PPV-positive predictive value; NPV-negative predictive value; -number

M-CHAT criteria: fail $\geq 2$ critical items (items $2,7,9,13,14,15$ ) or more than 3 out of 23 total items

The overall ROC curves for patients between the age of 18 to 60 months old are shown in Figures 2 . Based on the ROC curve, the optimal cut-off score to discriminate between ASD and other developmental-behavioural disorders for critical criteria was failing 1 out of the 6 critical items, giving rise to a sensitivity of $85.7 \%(95 \% \mathrm{Cl}=74.6$ 93.3) and specificity of $64.1 \%(95 \% \mathrm{Cl}=51.5-75.5)$. Whereas for the total criteria, failing 3 items out of the 23 total items will give a sensitivity of $88.7 \%$ $(95 \% \mathrm{Cl}=78.1-95.3)$ and specificity of $47.7 \%(95 \%$ $\mathrm{Cl}=35.4-60.3)$.
(A)

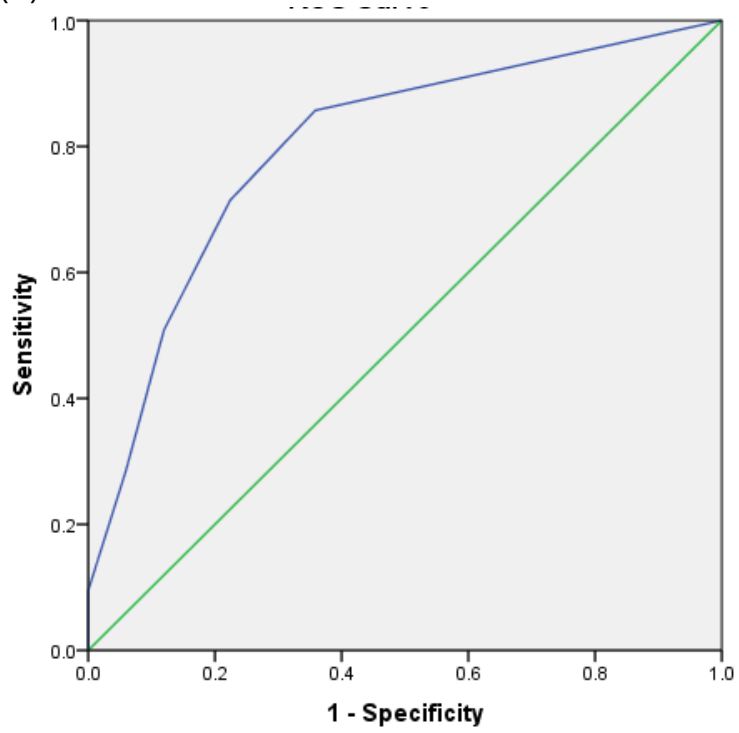

${ }^{*}$ Area under ROC curve (AUC): 0.800
(B)

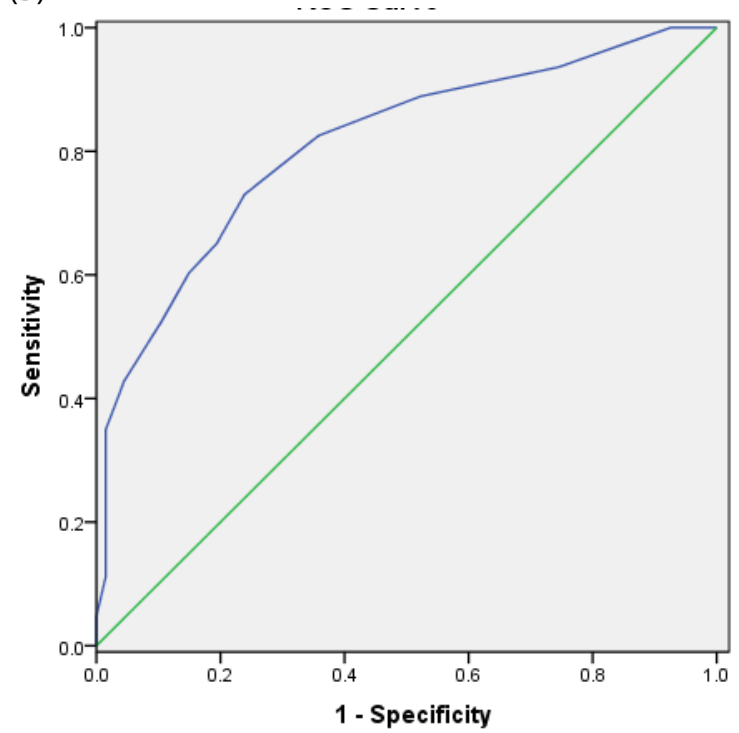

${ }^{*}$ Area under ROC curve (AUC): 0.811

Figure 2: ROC curve for (A) critical criteria and (B) total criteria (18-60 months old) 


\section{Discussion}

Our study showed that M-CHAT (MV) is a sensitive screening tool to differentiate ASD from other developmental-behavioural disorders within our population. This is an important additional feature of M-CHAT (MV) as it is not only useful in the general population, but it is also helpful in discriminating those who required further evaluation for ASD from other types of developmental-behavioural problems. To date, there are few studies that only used M-CHAT to differentiate between ASD and other developmental or behavioural disorders in children $[17,19]$.

Although almost $50 \%$ of the respondents did not use Malay as their primary language, only around $8 \%$ of the respondents needed assistance to complete the M-CHAT (MV). This indicates that the M-CHAT (MV) is easy to understand and use in a multi-cultural country. However, it should be noted that this is a selected population in an urban area where most of the parents had a high educational level (almost $85 \%$ of them received tertiary level education). Thus, it may not be representative of the actual general population.

In our study, the overall sensitivity of the M-CHAT (MV) was $88.9 \%$ which was almost similar with the study done by Snow et al which demonstrated a sensitivity of $88 \%$ [17]. The sensitivity level was also relatively comparable to the study done by Robins et al (sensitivity of $97 \%$ ) in the general population, especially for the 18-24 months old [10]. The specificity of our study was slightly higher in comparison to other studies conducted in children with underlying developmentalbehavioural disorders. The overall specificity for our study was $47.8 \%$ while the specificity in the study by Snow et al was 38\% [17]. As our study was performed in a more selected population involving a wider age group, the specificity was not surprisingly lower compared to studies involving the general population where the specificity was as high as $95 \%$.

Similar to the findings from Eaves et al and Snow et al, we found that the M-CHAT (MV) had lower sensitivity using the 2 critical items cut-off for children between the age of 37 to 48 months and 49 to 60 months old $(64.5 \%$ and $66.0 \%$ respectively) $[16,17]$. In Eaves et al, the sensitivity using the critical items was $77 \%$, whereas in Snow et al, the sensitivity was $70 \%[16,17]$. In our study, the positive predictive value (PPV) was $62 \%$, which was lower compared to Snow et al (PPV of 79\%)
[17]. The higher PPV in Snow et al could be attributed to the higher rate of ASD patients in her study compared to our study.

By plotting the ROC curve, the optimal cut-off score was failing 1 item from the 6 critical items instead of failing 2 items criteria as used by Robins et al [10]. Similarly, the study by Snow et al also supported a different cut-off score for the critical item (failing 1 critical item giving rise to sensitivity and specificity of $79 \%$ and $38 \%$ respectively) [17]. This could be due to the more selective high risk population group studied in our study and also in Snow et al. Future studies with a larger sample size are necessary to determine whether the critical criteria require any adjustment. The total criteria of failing any 3 items from the total of 23 items provided a good sensitivity for all the different age groups as shown in the ROC curve.

Due to the small sample size, the results in this study need to be interpreted with care. Further studies are required especially with recruitment of larger sample size in the various age groups to determine the optimal cut-off score for each individual age group.

\section{Conclusion}

M-CHAT (MV) is useful in differentiating children who require further ASD assessment from those with other developmental-behavioural disorders within our population. It has good sensitivity (>90.0\%) for children up to the age 48 months old and acceptable sensitivity (80.0\%) for children aged 49 to 60 months old. However, the critical items' criteria may need to be lowered in selected cohort of patients to increase the sensitivity to differentiate ASD from other developmentalbehavioural problems.

All the authors contributed to the conception and design of this study. DL performed the statistical analysis and drafted the manuscript. RJ, ZL and critically reviewed the manuscript and supervised the whole study process. All authors read and approved the final manuscript.

\section{Declaration of Interests}

The authors declare no conflict of interest.

\section{Funding Acknowledgement}

This study is funded by the National University of Malaysia. 


\section{Acknowledgement}

We would like to thank Dr. Diana L. Robins (Ph.D.) for allowing us to translate the original M-CHAT to the Malay version for the use of this study. We would also like to thank $\mathrm{Dr}$ Aminah Bee for her contribution in translating the M-CHAT to the Malay version.

\section{References}

[1] Diagnostic and Statistical Manual of Mental Disorders (4th Ed.) Washington, DC. American Psychiatric Association. 2000.

[2] Lord C, Risi S, DiLavore PS, Shulman C, Thurm A, Pickles A. Autism from 2 to 9 years of age. Arch Gen Psychiatry. 2006;63:694-701.

[3] Crais ER, Watson LR, Baranek GT, Reznick JS. Early identification of autism: how early can we go? Semin Speech Lang. 2006;27(3):143160.

[4] Chawarska K, Klin A, Paul R, Volkmar F. Autism spectrum disorder in the second year: stability and change in syndrome expression. J Child Psychol Psychiatry. 2007;48(2):128-138.

[5] Coo H, Ouellette-Kuntz H, Lam $M$, et al. Correlates of age at diagnosis of autism spectrum disorders in six Canadian regions. Chronic Dis Inj Can. 2012;32(2):90-100.

[6] Malaysia, Ministry of Health. Annual Health Report from the Division of Family Health Development. 2005.

[7] Trillingsgaard A, Ulsted Sørensen E, Nemec G, Jørgensen $M$. What distinguishes autism spectrum disorders from other developmental disorders before the age of four years? Eur Child Adolesc Psychiatry. 2005;14(2):65-72.

[8] Baron-Cohen S, Allen J, Gillberg C. Can autism be detected at 18 months? The needle, the haystack, and the CHAT. Br J Psychiatry. 1992;161:839-843.

[9] Robins DL. Screening for autism spectrum disorders in primary care settings. Autism. 2008;12(5):537-556.

[10] Robins DL, Fein D, Barton ML, Green JA. The modified checklist for autism in toddlers: an initial study investigating the early detection of autism and pervasive developmental disorders. J Autism Dev Disord. 2001;31(2):131-144.

[11] Pandey J, Verbalis A, Robins DL, Boorstein H, Klin AM, Babitz T, et al. Screening for autism in older and younger toddlers with the modified checklist for autism in toddlers. Autism. 2008;12(5):513-535.
[12] Kleinman JM, Robins DL, Ventola PE, Pandey J, Boorstein HC, Esser EL, et al. The modified checklist for autism in toddlers: a follow-up study investigating the early detection of autism spectrum disorders. J Autism Dev Disord. 2008;38(5):827-839.

[13] Wong V, Hui LH, Lee WC, Leung LS, Ho PK, Lau $W L$, et al. A modified screening tool for autism (checklist for autism in toddlers [CHAT-23]) for Chinese children. Pediatrics. 2004;114(2):e166-176.

[14] Inada N, Koyama T, Inokuchi E, Kuroda M, Kamio Y. Reliability and validity of the Japanese version of the modified checklist for autism in toddlers (M-CHAT). Res Autism Spectr Disord. 2011;5(1):330-336.

[15] Canal-Bedia R, Garcia-Primo P, Martin-Cilleros MV, Santos-Borbujo J, Guisuraga-Fernández Z, Herráez-Garcia L, et al. Modified checklist for autism in toddlers: cross-cultural adaptation and validation in Spain. J Autism Dev Disord. 2011;41(10):1342-1351.

[16] Eaves L, Wingert $H$, Ho H. Screening for autism: agreement with diagnosis. Autism. 2006;10(3):229-242.

[17] Snow AV, Lecavalier L. Sensitivity and specificity of the modified checklist for autism in toddlers and the social communication questionnaire in pre-schoolers suspected of having pervasive developmental disorders. Autism. 2008;12(6):627-644.

[18] Malaysia, Ministry of Health, Division of Family Health Development [in collaboration with United Nations Children's Fund (UNICEF)]. Proceedings. Meeting on Outcome of Pilot Screening for Autism and Action Plan. 16-18 May 2006.

[19] Ventola P, Kleinman J, Pandey J, Wilson L, Esser $\mathrm{E}$, Boorstein $\mathrm{H}$, et al. Differentiating between autism spectrum disorders and other developmental disabilities in children who failed a screening instrument for ASD. J Autism Dev Disord. 2007;37(3):425-436. 